\title{
Factors governing site selection of nuclear plants
}

\author{
M. B. HAFEZ (*) \\ (Manuscrit reçu le 6 avril 1976)
}

\begin{abstract}
The basic technical and economic criteria for the siting of nuclear power stations are discussed. These criteria are based on the emergency exposure of the general population to direct radiation, inhalation and environmental contamination. A regime is discussed to provide standards for site selection; the atmospheric release of biologically significant radionuclides is the most important factor. A number of other factors will influence the judgement, for example, population distribution, local geography, topography, hydrology, seismology and soil analysis. A careful economic evaluation of location at different alternative sites is necessary, taking into account the cost of cooling water-works, foundations and other engineering and social aspects.
\end{abstract}

\section{RÉSUMÉ}

Les critères techniques et économiques fondamentaux d'implantation des centrales nucléaires sont discutés. Ces critères reposent sur la dose à laquelle l'ensemble de la population serait exposée au cas d'accident du fait des rayonnements externes, de l'inhalation de particules radioactives et de la contamination. On présente un barème d'évaluation qui fournira des normes pour le choix des sites; la libération dans l'atmosphère de radionucléides est un des facteurs les plus importants. D'autres facteurs doivent être pris en considération comme la distribution de la population, la géographie, la topographie, l'hydrologie, la sismologie, la nature des sols. Une étude économique détaillée est nécessaire pour chacun des sites possibles, tenant compte du coût des installations de refroidissement par l'eau, des travaux de fondation, et des autres aspects techniques et sociaux.

(*) Radiation Protection Department, Atomic Energy Establishment, Cairo, Egypt. 


\section{INTRODUCTION}

The selection of a nuclear plant site is governed by many factors of varying importance. These may be conveniently divided into two groups. The first, being of primary importance, would mean automatic rejection of a proposed site if a requirement in this group was not fulfilled. Of secondary importance would be those factors which although influencing the final decision would not singly, if unfulfilled, result in site rejection.

The safety requirements of the proposed site were placed in the first group. We shall discuss the following: no danger of floods or earth-quakes, sufficient distance from densely populated areas, no interference with other important installations and no danger of contaminating important watersupply areas. Some technical requirements were also included in this primary group: the availability of a sufficient amount of water, means of waste disposal and the temporary storage of highly radioactive material e. g. used fuel elements, irradiated materials and radioactive waste.

Economic requirements such as low building and operating costs, social requirements such as attractive living conditions for employees, easy contact with other scientific institutes and the presence of schools, hospitals etc., belong to the second group.

\section{SAFETY REQUIREMENTS}

\subsection{Population Density}

Site analysis and evaluation are required to assess the relative safety of a proposed site under expected or estimated operating conditions as well as postulated accident or emergency situations. Such analysis and evaluation also provide data and information that assist in the establishment of the engineering criteria for containment, waste handling, operating control and other safety provisions. These may have to be built into the installation to assure compatibility of the proposed installation and the site with regard to adequate protection of public health and safety. The process and objective of site selection consist in obtaining an acceptable conclusion regarding the potential radiation effects of the installation on the local population and environment. The population density around a nuclear reactor site is therefore one of the main factors that influence the final decision on site acceptability.

Siting criteria vary more or less from country to country; however, there are two broad categories. The first is based on a system of reference doses used in conjunction with the maximum credible accident involving the reactor. Areas are defined around the site such that the reference doses are not exceeded. 
The second category proposed by Farmer and Bell depends upon the density and distribution of the surrounding population [2, 4]. The population distribution around the selected sites is examined in relation to a system of weighting factors derived from the dispersion of iodine and tritium in stable air conditions in down-wind direction. The product of population number and weighting factors is summed out to a range of $25-30 \mathrm{~km}$ from the reactor for several $30^{\circ}$ sectors. These products enable a relative rating to be calculated for each sector. The highest total obtained for any $30^{\circ}$ sector is termed the site rating. Sites are then classified according to their site rating into four classes.

In an overall assessment, different factors will be taken into account before a final judgment of the acceptability of a particular site is made. These factors cannot be readily expressed in numerical terms and their consideration must largely depend upon experience and the exercise of a degree of judgment. For example a site uniformly surrounded by population is less acceptable than a site in which the same population density exists only in a limited number of sectors. Another factor is the probable expansion of population towards the site which may occur during the expected long useful life of the nuclear plant.

\subsection{Climatological, meteorological, and physical features of the Site}

The climate of the area is very important in the preliminary studies and evaluations. A complete knowledge of the main factors that affect the climate of the area, mainly: the prevailing pressure systems, locality and orography must be taken into consideration. The weather must be moderate without long seasons of extreme heat, cold or precipitation and it would be preferable to choose an area of low humidity.

The meteorological calculations used to determine the maximum dose received at a specified distance are related to a specific meteorological situation and are important factors in the site selection. The two major meteorological factors involved in atmospheric transport and dilution of airborne contamination are wind and atmospheric stability (vertical temperature gradient) [9]. Listing of conventional wind measurements does not provide sufficient basis for the assessment of atmospheric transport and dispersion. As wind data provide only a partial answer, analysis and meteorological interpretation are essential. Climatological wind patterns at a proposed site should be examined in terms of not only the usual direction and speed frequency distribution, but also the probability distribution of the persistence of winds in given directions at a given speed. Therefore, the first step is generally to study the joint statistics of wind direction and wind speed.

Atmospheric diffusion is determined by four dimensional wind fluctuations [3]. These fluctuations (turbulence) are closely related to the vertical temperature gradient of the air. When the temperature decreases with height at a rate equal to or greater than the adiabatic rate $\left(1^{\circ} \mathrm{C} / 100 \mathrm{~m}\right)$ buoyance forces are free to act and turbulence is enhanced. When the temperature 
increases with height an inversion of stable situation exists, vertical motions are suppressed, and turbulence (and hence dispersion) is lessened.

\subsection{Geohydrological analysis}

The aim of geohydrological analysis is to help to determine what possible effect a reactor plant might have on surrounding water resources [7].

The analysis should contain as many basic facts concerning geology, topography, occurence of surface and ground water, and their interrelationships as may be necessary to provide an adequate picture of the overall hydrogeological regime. Underlying formations should be described, particular attention being paid to shallow aquifers if such exist. The direction and speed of ground-water flow should be determined or estimated. The drainage pattern and flow characteristics of surface streams that could be affected either by a contaminant in surface drainage or in atmospheric fall-out, should be described. Discharge duration curves and velocity profiles are useful in estimating available dilution and time of travel.

A description with map(s) should be provided of all existing water utilization that could possibly be affected by plant operation or accident. Areas that might be affected by fall-out or rain-out from an airborne contaminant should be included. An estimate should be made of future potential water utilization of the region. The existence or non-existence of alternative supplies or of stored water that could be used in an emergency should be indicated, particularly where municipal or industrial supplies are exposed to possible contamination.

The possible paths and rate of water movement should be investigated [1] without regard to possible effects between radioactive contaminants and earth materials; that is, the motion of the water itself, in its role as the transporting and dispersing agent, should first be determined. The path might be entirely in surface waterways or entirely in-subsurface soils and aquifers, or in a combination of both. The altitude of the water-table should be examined and shown on maps to trace the directions and gradient of ground-water flow.

\subsection{SoIL ANALYSIS}

The surface material should be examined for its effects on the infiltration of liquids and sorption of radioactive materials. With few exceptions radioactive contaminants dissolved or suspended in water are subject to sorption on earth materials with which they may be brought into contact [10]. Sorption will depend primarily on isotope species, the nature of earth materials and relative concentrations of all materials in solution both stable and radioactive.

A simple listing of data or descriptive information on the depth of the watertable, permeability, ion exchange capacity, ground-water usage and characteristics of formations or well logs etc., is inadequate. Such data and information should be interpreted to know the extent and nature of 
movement of potential contaminated liquid effluents and what the significance of such movement might be.

\subsection{Seismology}

The seismic history of a specific plant site and the surrounding region, and the appropriate seismic design criteria to be used for conventional types of structures must be established [6]. These are done in accordance with the generally accepted procedures. Because of the conservative safety reviews which are made of nuclear plants, more seismic design criteria are required than for any other type of facility.

The horizontal ground acceleration design criteria must be almost always greater than specified by the uniform building code. Within the same general area local earthquake intensities may vary considerably depending upon local soil conditions and distance from the epicenter of the earthquake [12]. On deep alluvium for example, ground acceleration may be amplified and may result in greater seismic intensities on the surface than would occur on more consolidated material located at the same distance from the epicentre of the same earthquake.

Measurements of the seismic response of the soil must be recorded. The seismic response is evaluated from modified spectra of recorded earthquakes at similar locations or in the vicinity of the site together with soil test boring and other geological investigations. This data provides an indication of the degree of amplification that might be expected at the site and consequently the earthquake intensity for which the plant should be designed.

\subsection{GeOLOGY}

Terrains liable to sliding, and tectonically active areas are to be avoided. Soils suitable for location of nuclear plants are those that have favourable retention properties to prevent contamination of ground water. A high water-table is unsuitable [8] owing to several factors such as the cost of foundation work and the amplification of seismic forces.

\section{TECHNICAL AND ECONOMICAL REQUIREMENTS.}

\subsection{LAND AVAILABILITY}

The cost of land is usually a very small fraction of the total development cost of a nuclear station. However, site costs can vary from one area to another. Although land cost reflects many land availability factors, it does not indicate the conservation or political difficulties involved in securing the site [5]. These factors are rapidly increasing in importance in many parts of the country as land availability decreases and demand for conservation increases.

vol. $11-\mathrm{N}^{0} 3$ 


\subsection{TRANSPORT AND COMMUNICATIONS}

As regards transportation facilities, the main points to be considered are requirements during the construction period [11]. Adequate roads or a proper railway network are required. If the plant is to be located on the coast, it may be more suitable to transport the most bulky parts by sea.

\subsection{LEVELS AND FOUNDATION}

The site should be flat and above high-tide level without any danger of flooding. Foundation conditions are important since each massive reactor structure can weigh up to 100,000 torrs and impose bearing pressures up to $120 \mathrm{t} / \mathrm{m}^{2}$.

\subsection{TeChNiCAL AND SOCIAL INVESTIGATIONS}

Once the preceding points have been taken into consideration, the selected sites must be compared with each other with respect to technical and social demands.

The primary requirements to be met are:

(1) Sufficient supply of drinking and industrial water.

(2) Direct disposal of low radioactive liquid.

(3) A town with at least 25,000 inhabitants at a distance of $25 \mathrm{~km}$ meeting social and cultural needs.

(4) Availability of energy, such as electricity, gas and oil.

(5) Accessibility for delivery of personnel, raw materials, final products, equipment and supplies.

(6) Social community facilities.

(7) Housing and education facilities.

(8) Availability of labour and services.

\section{REFERENCES}

[1] American Society of Civil Engineers, Hydrology Commitee. Hydrology handbook. ASCE, Manual of Engineering Practice, No 28, 1959.

[2] Bell G. D. and Charlesworth F. R. Safety principles for low and medium powered research reactors, In Siting of reactors and nuclear research centres, Vienna, IAEA, $1963,317$.

[3] Demarrais G. A. and Islitzer N. L. Diffusion climatology of the National Reactor Testing Station. USAEC, Idaho operation office, IDO-12015, 1960.

[4] FARMER F. R. "The Evaluation of power reactor site" DPR/1 NF/266.

[5] FAUX F. and Stone G. N. Experience in planning and siting nuclear power stations In Siting of reactors and nuclear research centres, Vienna, IAEA, 1963, 435.

[6] Horan J. R. et al., Annual Report of the Health and safety Division, Idaho operations office, IDO-12021, 1961. 
[7] Linsley R. K., Kohler M. A. and Paulus J. L. H. Applied hydrology. Civil Eng. Series, New York, McGraw-Hill, 1949.

[8] NACE R. L. et al. Geography, geology and water resources of the National Reactor Testing Station. US Geological Survey-NRTS, IDO-22033, Parts 2 and 3, 1956.

[9] Pasquill F. Atmospheric diffusion, London, Van Nostrand, 1962.

[10] Schmalz B. L. Interim Report on liquid waste disposal in the vicinity of the Idaho chemical processing plant, USAEC, IDO-12011, 1959.

[11] United States. Code of Federal Regulations, Reactor Site Criteria title 10, part 100, (10 CFR 100), 1961.

[12] World Reactor chart, 3rd ed., Nuclear Power, 1962. 